\title{
OPTIMIZATION OF PRODUCTIVITY OF SEATS USING TIME STUDY AND
}

$$
\text { ASSEMBLY LINE BALANCING }
$$

\section{MUDDINENI NARESH ${ }^{1}$, DHANUNJAY KUMAR AMMISETTI ${ }^{2}$, CH. SURESH ${ }^{3} \&$ PAKANATI ANIL KUMAR $^{4}$}

${ }^{1}$ Assistant Professor, Department of Mechanical Engineering, Vasireddy Venkatadri Institute of Technology, Andhra Pradesh, India

${ }^{2}$ Assistant Professor, Department of Mechanical Engineering, Lakireddy Bali Reddy College of Engineering, Andhra Pradesh, India

${ }^{3}$ Assistant Professor, Department of Mechanical Engineering, Vignan's Institute of Engineering for Women, Andhra Pradesh, India

${ }^{4}$ Assistant Professor, Department of Mechanical Engineering, Vignan's Institute of Engineering for Women,

Andhra Pradesh, India

\begin{abstract}
Line balancing is a production strategy that can be used to optimize the workstations or assembly line throughout. It helps to reduce the production time, reduce labor and maximizing output at lowest cost. This article represents case study problem in a company to develop the existing layout based on takt time and also to improve the labor productivity and machine utilization. In this work time study has conducted in order to calculate task time of every operation in the existing plant layout. The objective of this study is to balance the production line and also to improve the performance of the existing layout. The data used for this research work is collected from the company. The outcome of the research shows $12.84 \%$ improvement in production line efficiency after line balancing. Hence this study recommends that the company should adopt the proposed layout and replacing the existing layout with a new one for getting higher productivity.
\end{abstract}

KEYWORDS: Productivity; Assembly Line Balancing; Line Efficiency, Takt Time, Cycle Time; Bottleneck

Received: Jun 10, 2020; Accepted: Jun 30, 2020; Published: Jul 17, 2020; Paper Id.: IJMPERDJUN2020364

\section{INTRODUCTION}

In the present scenario optimization of layout in industry plays an important role to increase the productivity of an organization. Productivity is the ratio of output to input $\&$ it is a quantitative relationship between output and input. In other words, productivity means to increase more output compared with inputs. Here final product is the output and men, time, machine, material etc. are considered as inputs. Gerald R. Aase et al. experimentally studied the UShaped assembly line layouts and their impact on labor productivity. Their results indicate that an average $10 \%$ improvement in labor efficiency while using simple $U$ line balancing compared with straight assembly line balancing. The improvement of labor productivity is also depending upon the demand periods (Aase, Olson, \& Schniederjans, 2004).ArtunTörenli studied assembly line design and optimization. The thesis shows that the unbalanced assembly line causes more captive losses. the conventional line balancing methods not useful when the operations are more than hundreds and the properties of the products changes continuously. So, in the current thesis Prop lanner line balance software is used as a tool and replacing the conventional line balancing methods for best balancing. The maximum $40 \%, 29 \% \& 90 \%$ reduction in working process, operation time and takt time overdue 
respectively were observed by using Pro planner tool compared to existing plant layout(Development, 2009).Sudharsan Sridhar et.al experimentally studied Balancing of Production Line in a Bearing Industry to improve Productivity. They are used two platforms one is rearranging of tasks and second one is Timer Pro Professional software for finding optimal productivity. The production of bearings increased by 4628 bearings using rearranging tasks and 55,770 bearings by Times Pro Professional software (Sridhar, 2017). D. Battini et. Al develops a theoretical model to improve the productivity and also made a relationship between ergonomics and assembly. The objective of their study indicates how the assembly line design depends on technical factors and environmental factors(D Battini, Faccio, Persona, \& Sgarbossa, 2011).Daria Battini et.al studied efficiency of assembly line balancing based on energy consumption. They proposed a multi objective approach for balancing and they moved from time optimal solution to energy optimal solution(Daria Battini et al., 2016). AdilBaykasoglu et.al used ant colony optimization technique to balancing parallel assembly lines. They consider the following critical factors such as increasing productivity and flexibility and reducing failure and minimizing cost. Parallel assembly line balancing is very useful when the capacity of plant is insufficient. Their study compares the ant colony optimization algorithms with other optimization algorithms(Baykasoglu, Ozbakir, Gorkemli, \& Gorkemli, 1991). Christian Becker et.al made a survey on problems and methods in assembly line balancing methods. Their survey indicates that initially assembly line balancing focused on simple assembly line balancing problems and then it is used gradually for general assembly line balancing problems. They suggested to develop an optimal software for best balancing (Becker \& Scholl, 2006).Nils Boysen et.al studied about assembly line balancing and their corresponding models. Their study indicates the gap between research status and real-world problems in the assembly line balancing (Boysen, Fliedner, \& Scholl, 2008). Mayron César O. Moreira et.al studied robust assembly line balancing with heterogenous workers. Their study focused on task times in assembly line which are dependent on workers and other factors. They developed robust insertion constructive heuristic procedure for yielding optimal balancing with heterogenous workers(Moreira, Cordeau, Costa, \& Laporte, 2015). MohdFadzilFaisae Rashid et.al reviewed assembly sequence planning and assembly line balancing optimization techniques through soft computing approaches. Their study discussed about the challenges in ASP and ALB such as optimisation process and the gap between models with actual industrial problems(Fadzil, Rashid, \& Hutabarat, 2012). Ihsan Sabuncuoglu et.al discussed Ant colony optimization for the single model U-type assembly line balancing problem. They compared the ACO algorithm with other algorithms and observed good optimal results from ACO algorithm(Sabuncuoglu, Erel, \& Alp, 2009).

In the current thesis we have studied the effect of cycle time and manpower on productivity. We considered cycle time as the tool to calculate each workstation's productivity. The critical time for each activity will be decided at each work station, which takes the longest cycle time and the output of the layout depends on that workstation. So, in order to increase the productivity, we have to reduce bottleneck of the activity time. HaritaFehrer Limited is joint venture between Harita seating systems Pvt. Ltd. and F.S. Fehrer Automotive GmbH, Germany. This organization is specialized in manufacturing of Polyurethane foam pads and two/three-wheeler seat assembly. This study is carried out at HaritaFehrer Limited to optimize the man power and cycle time and observe the production efficiency for the assembling of C5-Model Pillion seats.

\section{METHODOLOGY}

In the current thesis we have used micro motion study for improvement of work activities. In micro motion study by using camera taken the motion pictures of various activities or movements and analyze them to improve the performance of work. This study is based on the idea of dividing human activity into division of movements. Micro motion study is one of the most 
accurate techniques for work analysis used for work improvement. The various sub parts of C5- Model pillion seat shown in table 1 and the diagrammatic representation of the parts shown in Figure 1.

The pillion seat assembly carried out by the fallowing 9 steps and the steps shown in the Table $2 \&$ the layout of assembly line is shown in Figure 2 i.e. a parallel line assembly layout and the schematic representation of layout shown in Figure 3. The assembly line Consists 3 workstations and carried out the 8 processing steps. The manpower required in this layout was 10 implementing lean manufacturing technology in the parallel assembly line, we reduce the manpower and cycle time and enhances the productivity.

Table 1: Sub Parts of C5-Model Pillion Seat

\begin{tabular}{ll} 
S. No & Subpart Name \\
\hline 1 & Pillion metal base \\
2 & Pillion foam \\
3 & Refresh Upholstery \\
4 & Refresh 2017 Upholstery \\
5 & Chrome Upholstery \\
6 & Upholstery black \\
7 & Beading wire \\
\hline
\end{tabular}

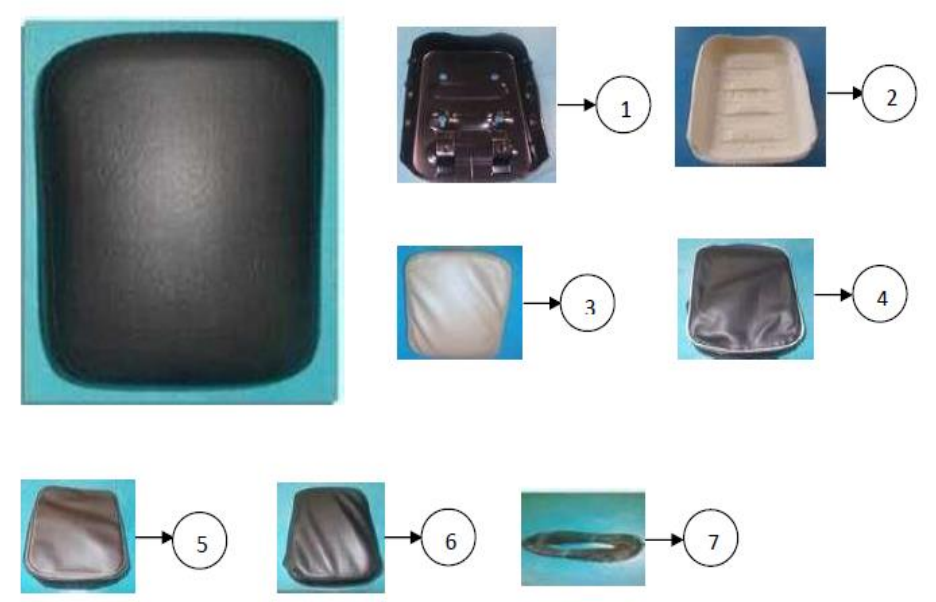

Figure 1: C5-Modelpillion Seat Subassembly Parts.

Table 2: Steps to Make the Pillion Seat Assembly

\begin{tabular}{ll}
\hline Step No & Description \\
\hline 1 & Spraying of glue to the foam \\
2 & Glue spraying to the seat cover \\
3 & Applying glue to metal base \\
4 & Beading of metal base \\
5 & Attaching seat foam, base and cover \\
6 & Tightening \\
7 & Punching \\
8 & Applying anabond \\
9 & Inspection \\
\hline
\end{tabular}




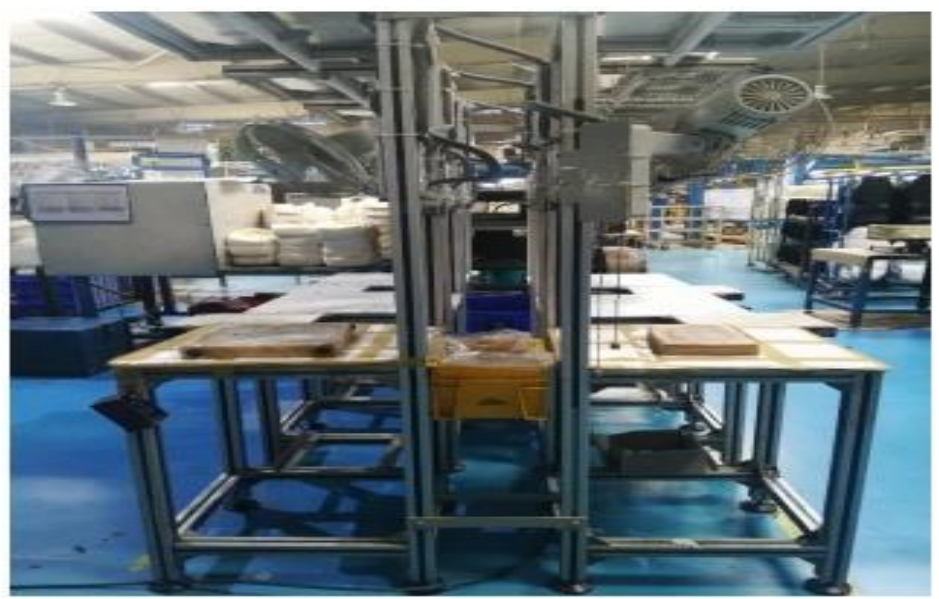

Figure 2: Pictorial View of Existing Parallel Assembly Layout.

\section{DATA COLLECTION}

The data collected from the seat assembly line and applied micro motion study to improve the productivity. The contents of the collection data are summarized and shown in the Table 3 and observed that the attaching seat assembly taken highest time which is $36.6 \mathrm{sec}$. The takt time is the ratio of available time to the demand and number of operators required is the ratio of total time to takt time. The details of the demand, takt time and number of operators are shown in the Table 4.

By using the micro motion time study data analysis was done and plotted a bar chart shown in Figure 3 and the schematic representation of existed layout is shown in Figure 4. From the bar chart we have found that operation 5 exceeds the takt time and remaining operations are completed within the takt time. Reduction of the gap between takt time and activity time helps in obtaining the optimum productivity. After giving recommendations to the industry, we have computed the Optimized layout with the help of micro motion study for optimization of assembly layout and it is shown in Table 5. The details of the demand, takt time and number of operators are shown in the Table 6.

Table 3: Summary Sheet of Cycle Time for Each Activity of Existing Layout

\begin{tabular}{lll} 
S. No & Operation & Time for Activity (Sec) \\
1 & Applying glue to metal base & 12.4 \\
2 & Beading & 17.4 \\
3 & Gluing seat foam & 15.2 \\
4 & Applying glue to seat cover & 20.2 \\
5 & Attaching seat assembly & 36.6 \\
6 & Pressing seat cover towards base & 29.4 \\
7 & Applying anabond & 12.4 \\
8 & Punching & 19 \\
\hline
\end{tabular}

Table 4: Summary Sheet of Demand, Takt Time and Number of Operators for Existing Layout

\begin{tabular}{lll}
\hline S. No & Description & Count \\
\hline 1 & Demand / day & 2400 \\
2 & Demand / shift & 800 \\
3 & Available time / shift & 24480 \\
4 & Takt Time & 30.6 \\
5 & Number of Operators & 7 \\
\hline
\end{tabular}


Table 5: Summary Sheet of Task Time for Each Operation of the Optimized Layout

\begin{tabular}{lll} 
S. No & Operation & Time for Activity (Sec) \\
\hline 1 & Applying glue to metal base & 12.4 \\
2 & Beading & 17.4 \\
3 & Gluing seat foam & 15.2 \\
4 & Applying glue to seat cover & 20.2 \\
5 & Attaching seat assembly & 22.2 \\
6 & Attaching seat cover at sides & 30.95 \\
7 & Punching & 22.4 \\
8 & Pressing seat cover towards base & 26.2 \\
9 & Applying anabond & 23.5 \\
\hline \multicolumn{2}{c}{ Total time } \\
\hline
\end{tabular}

Table 6: Summary Sheet of the Demand, Takt Time and Number of Operators for Optimized Layout

\begin{tabular}{lll} 
S. No & Description & Count \\
\hline 1 & Demand / day & 2400 \\
2 & Demand / shift & 800 \\
3 & Available time / shift & 24480 \\
4 & Takt Time & 30.6 \\
5 & No of Operators & 7 \\
\hline
\end{tabular}

\section{RESULTS AND ANALYSIS}

Micro motion study is used for the analysis of the data and plotted bar chat with task time of each activity Vs No. of Operations and takt time as shown in the Figure 3. From the micro-motion time study data, we calculated the various output parameters like maximum output of the assembly, line balancing efficiency and balance delay efficiency from the given input parameters.

The maximum output of the plant $=$ Available time/cycle time

$$
=24480 / 36.6=668.85 \text { units } / \text { shift }
$$

Line efficiency $(\mathrm{LE})=$ sum of task times $/($ no. of operations $*$ cycle time $)$

$$
\begin{aligned}
& =162.6 /(8 * 36.6) \\
& =55.54 \%
\end{aligned}
$$

Balance delay $(\mathrm{BD})=(\mathrm{m} *$ cycle time - total task time $) /(\mathrm{m} *$ cycle time $)$

Where $\mathrm{m}=$ number of operations

$$
\begin{aligned}
& =(8 * 36.6-162.6) /(8 * 36.6) \\
& =44.46 \%
\end{aligned}
$$

After performing the analysis, recommendations were given regarding modifications in the layout i.e. from parallel layout to series layout. These modifications help in increased productivity of seat assembly. The number of workers in this layout are 9 which are less in number than existing layout. The proposed optimized layout was shown in the Figure 5 and 
the bar chat for optimized assembly line layout shown in Figure 6 and the schematic representation of optimized layout shown in Figure 7.

From the bar chart we have observed that almost all operations complete before the takt talk and only operation 6 task times slightly exceeded the takt time but that difference between the times was negligible. The pie charts of line efficiency and maximum output/shift are shown in Figure $8 \& 9$. From the micro motion time study data, we can find the information about proposed assembly line layout. They are given below:

The maximum output of the plant $=$ available time/cycle time

$$
=24480 / 30.95=790.95 \text { units/shift }
$$

Line efficiency, $\mathrm{n}=$ sum of task times/ (no. of operations $*$ cycle time)

$$
\begin{aligned}
& =190.45 /(9 * 30.95) \\
& =68.37 \%
\end{aligned}
$$

Balance delay $=(\mathrm{m} *$ cycle time - total task time $) /(\mathrm{m} *$ cycle time $)$

Where $\mathrm{m}=$ number of operations

$$
\begin{aligned}
& =(9 * 30.95-190.45) /(9 * 30.95) \\
& =31.63 \%
\end{aligned}
$$

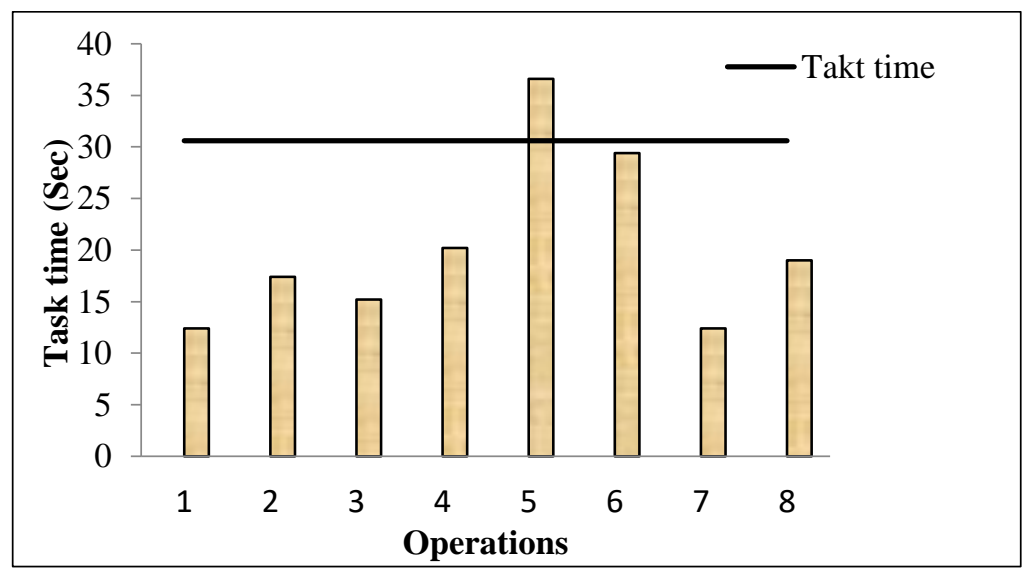

Figure 3: Bar Chart for Existed Assembly Line Layout.

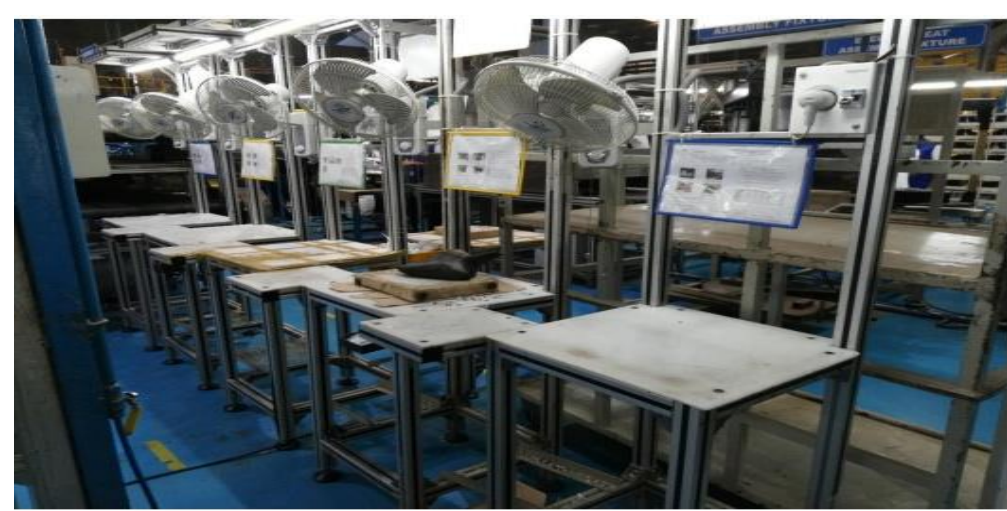

Figure 5: Pictorial View of Optimized Assembly Line Layout in Series. 


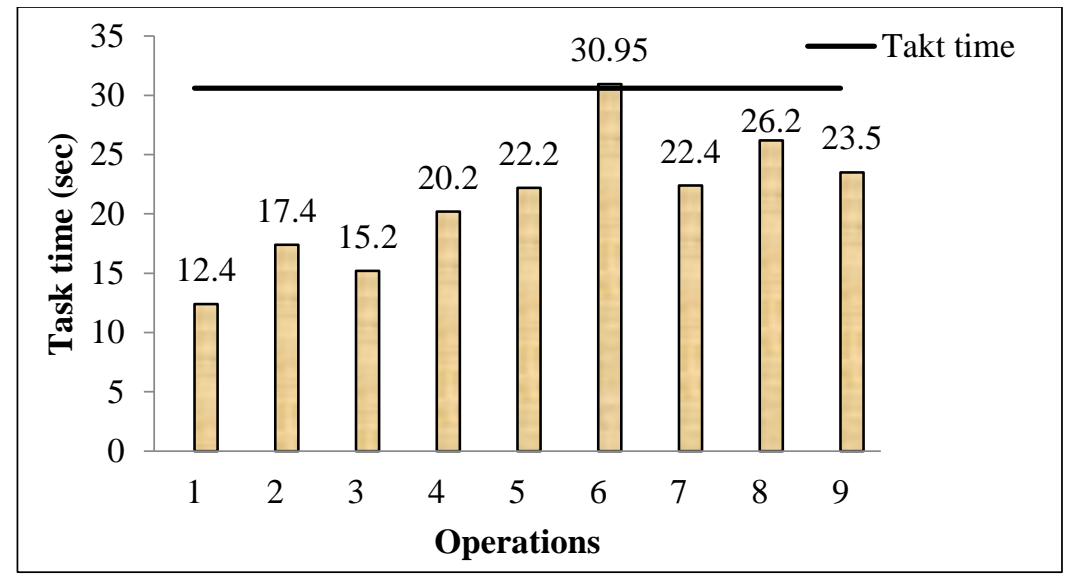

Figure 6: Bar chart for Optimized Assembly Line Layout.

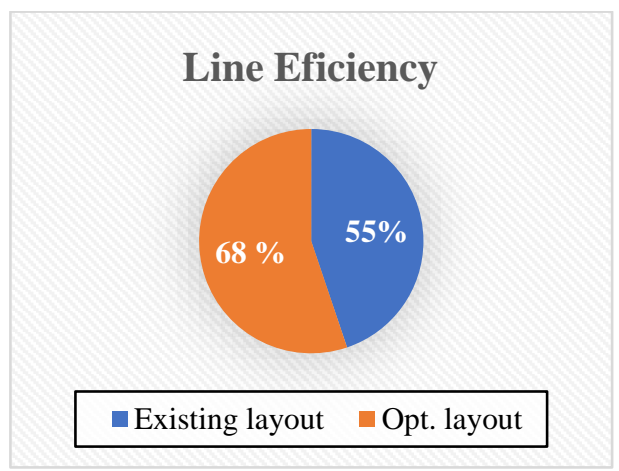

Figure 8: Line Efficiency

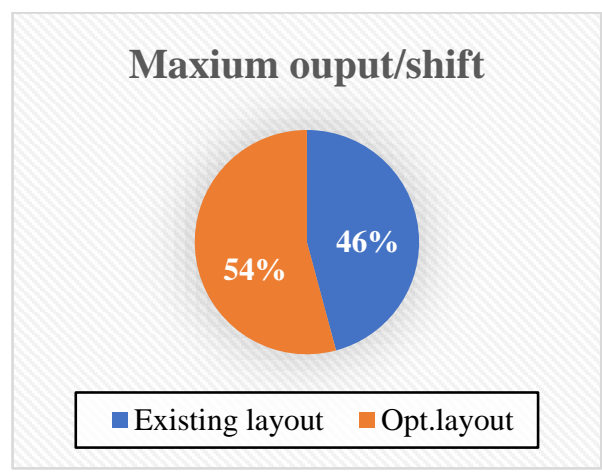

Figure 9: Maximum Output of the Plant.

\section{CONCLUSIONS}

The current thesis deal with a case study problem in a company to develop the existing layout based on time study and assembly line balancing. The results indicate that improved labor productivity and machine utilization. From the results and analysis of both the layouts it was found that an increase of $12.84 \%$ in line efficiency and the maximum output was increased to 790.95 from 668.85 . This study also recommended that the company should adopt the proposed layout in place of existing layout for achieving optimized productivity.

\section{REFERENCES}

1. ase, G. R., Olson, J. R., \& Schniederjans, M. J. (2004). U-shaped assembly line layouts and their impact on labor productivity : An experimental study. 156, 698-711. https://doi.org/10.1016/S0377-2217(03)001486.

2. Battini, D, Faccio, M., Persona, A., \& Sgarbossa, F. (2011). International Journal of Industrial Ergonomics New methodological framework to improve productivity and ergonomics in assembly system design. International Journal of Industrial Ergonomics, 41(1), 30-42. https://doi.org/10.1016/j.ergon.2010.12.001.

3. Battini, Daria, Delorme, X., Dolgui, A., Persona, A., Battini, D., Delorme, X., ... Persona, A. (2016). Ergonomics in assembly line balancing based on energy expenditure : a multi-objective model. International Journal of Production Research, 7543, 0. https://doi.org/10.1080/00207543.2015.1074299.

4. Baykasoglu, A., Ozbakir, L., Gorkemli, L., \& Gorkemli, B. (1991). Balancing Parallel Assembly Lines via Ant Colony Optimization. 506-511. 
5. Becker, C., \& Scholl, A. (2006). A survey on problems and methods in generalized assembly line balancing. 168, 694-715. https://doi.org/10.1016/j.ejor.2004.07.023.

6. Boysen, N., Fliedner, M., \& Scholl, A. (2008). Assembly line balancing: Which model to use when ?111, 509-528. https://doi.org/10.1016/j.ijpe.2007.02.026.

7. Development, P. (2009). Assembly line design and optimization.

8. Fadzil, M., Rashid, F., \& Hutabarat, W. (2012). A review on assembly sequence planning and assembly line balancing optimisation using soft computing approaches. 335-349. https://doi.org/10.1007/s00170-011-3499-8.

9. Moreira, M. C. O., Cordeau, J., Costa, A. M., \& Laporte, G. (2015). Robust Assembly Line Balancing with Heterogeneous Workers. COMPUTERS \& INDUSTRIAL ENGINEERING. https://doi.org/10.1016/j.cie.2015.07.004.

10. Sabuncuoglu, I., Erel, E., \& Alp, A. (2009). Int. J. Production Economics Ant colony optimization for the single model U-type assembly line balancing problem. Intern. Journal of Production Economics, 120(2), 287-300. https://doi.org/10.1016/j.ijpe.2008.11.017.

11. Sridhar, S. (2017). Balancing of Production Line in a Bearing Industry to improve Productivity Balancing of Production Line in a Bearing Industry to Improve Productivity. 9(2).

12. YADAV, ASHISH, and SUNIL AGRAWAL. "A multi-manned parallel two-sided assembly line balancing with tool sharing approach-A company case study solved by exact solution approach." International Journal of Mechanical and Production Engineering Research and Development (IJMPERD) 9.2 (2019): 5160.

13. REDDY, K. PALAKSHA, et al. "CYCLE TIME REDUCTION STUDIES IN THREADING." International Journal of Mechanical and Production Engineering Research and Development (IJMPERD) 8.2 (2018):149156.

14. SAHU, SUPRIYA, and BB CHOUDHURY. "CYCLE TIME OPTIMIZED PATH PLANNING FOR INDUSTRIAL ROBOT USING ROBOMASTER." International Journal of Mechanical and Production Engineering Research and Development (IJMPERD) 7.5 (2017):95102.

15. RAHMAN, MOHIBUR, et al. "THROUGHPUT ANALYSIS OF TCP NEWRENO FOR MULTIPLE BOTTLENECKS." International Journal of Computer Networking, Wireless and Mobile Communications (IJCNWMC) 7.2 (2017): 1928. 


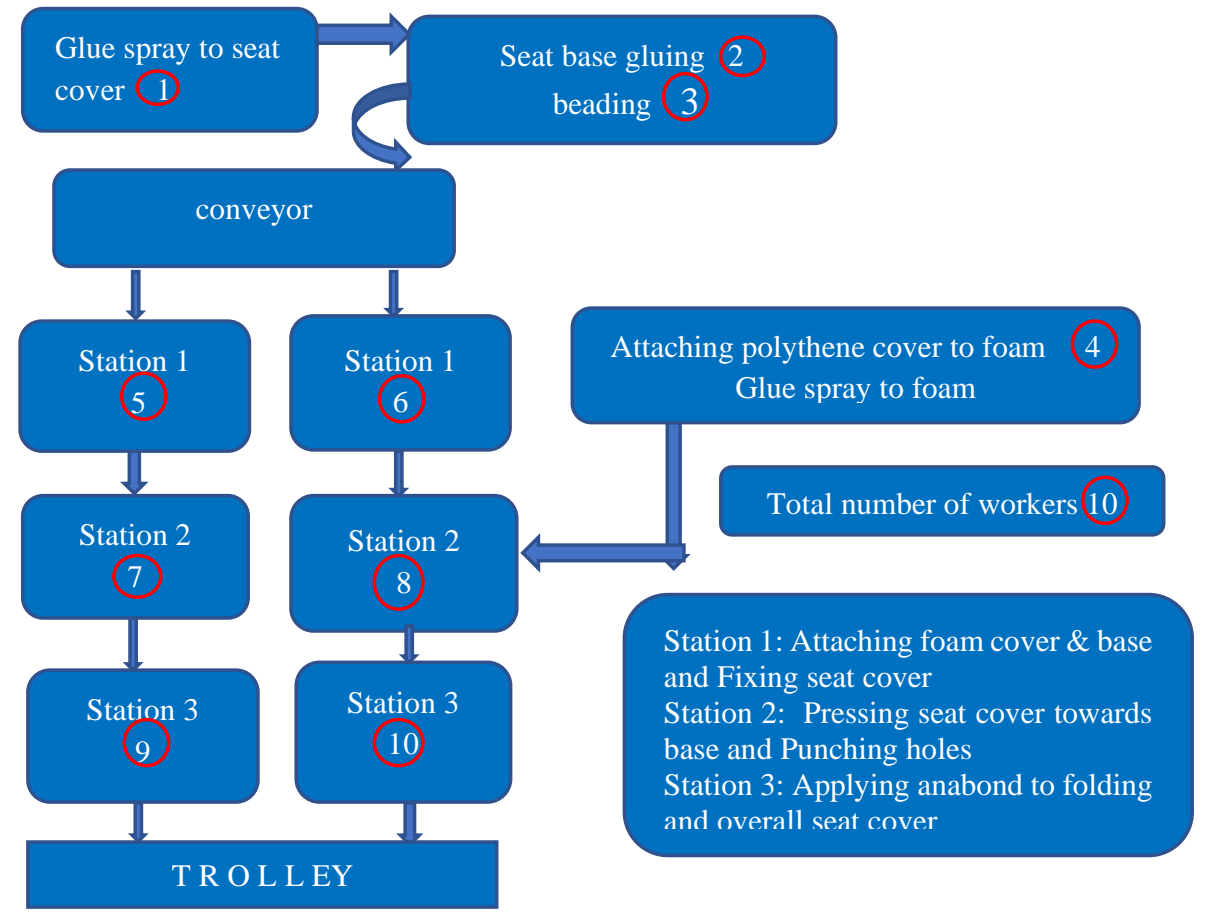

Figure 4. Schematic Diagram of Existed Assembly Line Layout

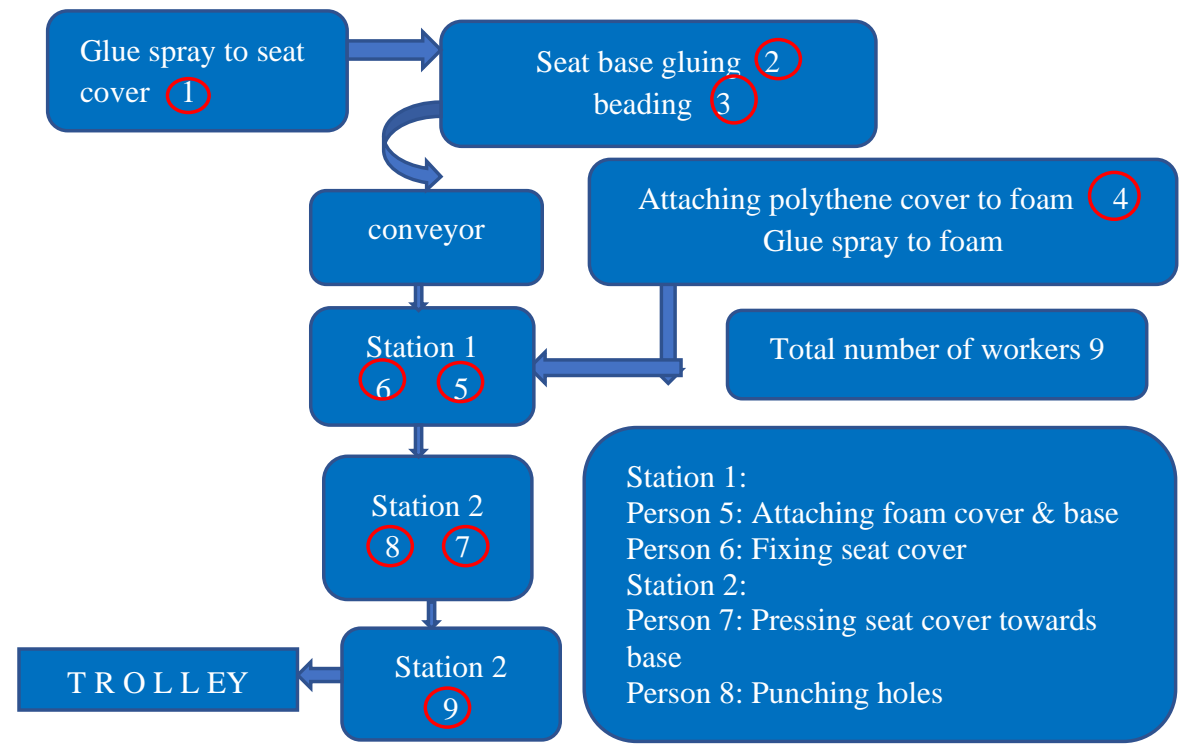

Figure 7. Schematic Diagram of Optimised Assembly Line Layout 
